\title{
Bryozoans Species Composition in Colombo Port with a Description of Two New Species
}

\author{
Marasinghe M.M.K.I. ${ }^{1}$, Ranatunga R.R.M.K.P. ${ }^{*}$ and Anil A.C. ${ }^{2}$ \\ ${ }^{I}$ Department of Zoology, University of Sri Jayewardenepura, Sri Lanka \\ ${ }^{2}$ National Institute of Oceanography, Dona-Paula, India \\ *ranatunga@sjp.ac.lk
}

\begin{abstract}
Biofouling is one of the major means of introducing organisms in to new marine environments. Bryozoans form the major component of the biofouling community. There is dearth of information on their presence in our waters. Therefore, systematic description on existing biofouling species in Sri Lankan coastal region is very essential. This paper describes the composition of bryozoans of the class Gymnolaemata with a description of two new species recorded from coastal waters of Sri Lanka.

The study was conducted in Colombo Port, one of the busiest ports in the country as well as in the region with an increased vulnerability for the introduction of geographically distinct species along with increased shipping operations. Monthly samples were collected from eight sampling stations using artificial settlement collectors which consisted of rope backbone supporting a number of horizontal PVC pipe arms that were attached to the settlement surfaces. The collectors were submerged systematically where first level was $1 \mathrm{~m}$ below the water surface and others setting at $1 \mathrm{~m}$ intervals. Species were identified microscopically observing fine morphological features. Scoring percentage covered by each bryozoan was determined using a quadrat (400 squares each with $5 \mathrm{~mm} \times 5 \mathrm{~mm}$ area).

During the study, seven species of the class Gymnolaemata were recorded namely; Electra bengalensis, Hippoprina indica, Celleporaria volsella, Parasmittina sp., Schiporella errata, Watersipora subtorquata and Sinoflustra annae. According to the One way ANOVA test there is a significant difference $(\mathrm{p}<0.05)$ between each sampling location for species richness and total percentage cover. However, there was no significant difference ( $p>0.05)$ between four sampling depths for species richness and total percentage cover.

Two new bryozoans identified were Sinoflustra annae and Electra bengalensis. Percentage cover of $S$. annae and E. bengalensis ranged from 1-18\% and 0.3-40\% respectively. Among these, E. bengalensis was recorded in all sampling stations yet $S$. annae was recorded only in CICT, BQ, OP and UCT. Though, these species are native to India, there are no published literatures for the presence of Sri Lankan coastal waters. Therefore, present finding will be the first record for their presence in Sri Lanka.
\end{abstract}

Keywords: Bryozoans, Species richness, Percentage cover, Colombo Port, Sinoflustra annae, Electra bengalensis

Proceedings of the International Forestry and Environment Symposium 2016, Department of Forestry and Environmental Science, University of Sri Jayewardenepura, Sri Lanka. 